\title{
Regulando el fin de la esclavitud Diálogos, innovaciones y disputas jurídicas en las nuevas repúblicas sudamericanas 1810-1830'
}

\author{
por Magdalena Candioti
}

Abstract. - The main purpose of this work is to elucidate the moment of strong experimentation and legal innovation, regarding slavery's regulation and its end, that opened up in some of the Hispanic American new republics between 1810 and 1830. The article reconstructs some of the legal tools and models of abolition that were thought and discussed by elites and used, and sometimes debated, by subaltern subjects that were part of these legal spaces in process of redefinition and construction. The legal tools discussed were the "free womb" laws, the patronage on freed blacks, the idea of "free soil", the abolition of the slave trade, and immediate abolition of slavery. The article reflects on the logic of these measures as well as on the explicit or implicit borrowings among elites that were creating a new way of relationship with the populations of African descent, the regulation of their work and its possibilities to access to citizenship in the new legal and political orders. At the same time, it argues that the letter of the law did not involve immediate changes in the condition of the enslaved since they had to fight over its interpretation in order to really acquire rights and improve their lives.

\section{Introducción}

El objetivo de este trabajo es reflexionar sobre el momento de fuerte experimentación e innovación jurídica que se abrió en Hispanoamérica entre 1810 y 1830 poniendo eje en los diálogos entre las naciones en construcción en

1 Agradezco al Instituto Max-Planck de Historia Jurídica Europea la posibilidad de realizar una estancia de investigación y consultar su biblioteca que fue vital para este trabajo. También, más recientemente, la investigación fue posible gracias a la beca de la Fundación Slicher Van Bath de Jong para la promoción del estudio y la investigación de la historia de América Latina, 2014. 
torno a la regulación de la esclavitud y su fin. El trabajo reconstruye algunos de los instrumentos jurídicos y modelos de abolición que pensaron y discutieron las élites de las nuevas repúblicas latinoamericanas frente al creciente consenso sobre la ilegitimidad de la institución esclavista. Entre ellos se cuentan las leyes de libertad de vientres, de patronato de libertos, la idea de "suelo libre", la abolición de la trata, la abolición gradual o inmediata de la esclavitud y las compensaciones a los dueños de esclavos. A partir del análisis de este corpus se reflexiona sobre la lógica de estos dispositivos así como sobre los préstamos explícitos o implícitos que fueron conformando un nuevo modo de vinculación con la población afrodescendiente, con la regulación del trabajo y sus posibilidades de acceder a la ciudadanía. En segundo lugar, se intenta rastrear algunos usos populares de tales leyes y cómo ellas fueron conocidas, imaginadas y utilizadas por sectores subalternos, ya sea en manifestaciones colectivas o en acciones judiciales individuales.

Los casos seleccionados son los de las actuales Argentina, Chile y Colombia. Ellos, por un lado, fueron espacios que desplegaron tempranamente políticas de reforma de la institución esclavista y, por diversas vías, observaron mutuamente y discutieron sus proyectos y procesos. Por otro lado, se trata de países latinoamericanos cuyas aboliciones fueron tradicionalmente poco estudiadas - ya sea por no haber desarrollado economías de plantación, algunos por no poseer visiblemente grandes proporciones de población afrodescendiente $\mathrm{y} / \mathrm{u}$ otros posiblemente por no haber tenido grandes movimientos de opinión abolicionistas - y que presentan similitudes que reseñaremos.

Lo que el trabajo intenta resaltar son centralmente dos cuestiones. En primer lugar, busca reflexionar sobre cómo la regulación del fin de la esclavitud - lejos de tratarse de un proceso de mera adaptación local o aplicación de innovaciones pensadas y diseñadas en primer lugar en Europa ${ }^{2}$ - fue un proceso que se desplegó con creatividad y que incluso pudo adquirir los contornos más radicales en este lado del Atlántico ${ }^{3}$. Es frecuente que las historiografías nacionales rastreen los lazos europeos del abolicionismo e interpreten la abolición de la trata negrera en el continente americano como consecuencia directa de las presiones inglesas contra ese comercio (del que

2 Para una crítica de esta visión ver, Thomas Duve, "European Legal History - Global Perspectives": Max Planck Institute for European Legal History Research Paper Series 6 (2013).

3 El trabajo de David Geggus ha sido crucial mostrar estas interacciones y la centralidad de las colonias en la configuración y políticas metropolitanas. Ver centralmente Geggus, "Racial Equality, Slavery and Colonial Secession During the Constituent Assembly": American Historical Review 94/5 (1989), pp. 1290-1308 y Geggus (ed.), The Impact of the Haitian Revolution in the Atlantic World (Columbia 2001). 
había sido protagonista por dos siglos). Sin negar la centralidad de esa campaña y del abolicionismo europeo, nos interesa aquí subrayar o sumar otras conexiones y diálogos jurídicos en curso. Dada la ausencia de una tradición de investigación historiográfica comparada sobre la dimensión legal de la esclavitud y la abolición en los países bajo estudio, pensamos que el intento de romper la tendencia a enfocarse exclusivamente en casos "nacionales" y a no considerar más que el texto de la ley, a no problematizar sus supuestos, a identificarla con su efectividad, es importante ${ }^{4}$.

Un segundo énfasis se pone en la reconstrucción de la secuencia cronológica de los debates y leyes sancionadas con el fin de evitar anacronismos y de poder dar cuenta de los términos del diálogo contemporáneo sobre la regulación del fin de la esclavitud, de las opciones conocidas, pensadas posibles y discutidas en este espacio jurídico plurisecular (el americano colonial) en proceso de incierta reconfiguración y recreación. En este sentido, los debates sobre la conveniencia de abolir o no y cómo la esclavitud, son parte de uno más amplio sobre la redefinición de la legitimidad (quién y porqué debe mandar), la ciudadanía (quienes son los sujetos soberanos y pueden integrarse plenamente a la nueva república) y la legalidad (quién

${ }^{4}$ Si ampliamos la mirada más allá de estos países, es posible encontrar desde los años cuarenta una literatura sobre esclavitud y derecho con un fuerte énfasis comparado en otras latitudes. El trabajo señero en este sentido fue Slave and Citizen. The Negro in the Americas (New York 1963) de Frank Tannnenbaum, quien propuso una comparación entre los sistemas esclavistas anglosajones e iberoamericanos. Más allá de las críticas cosechadas por este trabajo (que discutieron la idea de la ausencia de regulaciones sobre esclavitud en el mundo anglosajón; el carácter "benigno" en términos relativos de la esclavitud iberoamericana y la suposición de que la existencia de tales tradiciones legales equivalían a su aplicación y vigencia) es interesante la tradición de debates que el libro abrió y todo el campo de estudios sobre derecho, justicia y esclavitud que se desplegó en adelante. Para un balance de los debates surgidos alrededor de la propuesta de Tannenbaum ver el dossier coordinado por Alejandro De la Fuente/María Elena Díaz/Christopher Schmidt-Nowara, "Forum. What Can Frank Tannenbaum Still Teach Us About The Law Of Slavery?": Law and History Review 22 (2004) y Keila Grinberg, "Alforria, direito e direitos no Brasil e nos Estados Unidos": Estudos Históricos 28 (2001), pp. 63-83. Buenos ejemplos de la potencialidad del cruce entre historiografías jurídica y esclavitud - a veces con énfasis comparados más bien implícitos son: Rebecca J. Scott, "Reclaiming Gregoria's Mule. The Meanings of Freedom in the Arimao and Caunao Valleys, Cienfuegos, Cuba, 1880-1899": Past and Present 170 (2001), pp 181-217; Keila Grinberg, Liberata. A lei da ambigüidade. As ações de liberdade da Corte de Apelação do Rio de Janeiro no século XIX (Río de Janiero 2008). Carlos Aguirre, Agentes de su propia libertad. Los esclavos de Lima y la desintegración de la esclavitud, 1821-1854 (Lima 1993); Christine Hünefeldt, Paying the Price of Freedom. Family and Labor among Lima 's Slaves, 1800-1854 (Berkeley 1994). Hebe Mattos, Das cores do silêncio. Os significados da liberdade no Sudeste escravista. Brasil, século XIX ( $3^{\circ}$ ed., Campinas 2013) y Joseli Maria Nunes Mendonça/Silvia Hunold Lara (eds.): Direitos e justiças no Brasil (Campinas 2006), entre otros. 
define lo permitido y lo prohibido y cómo lo hace). En este sentido pensamos que el debate aquí rastreado jugó dos roles centrales en la construcción de las nuevas naciones: limitar la ciudadanía de la población afrodescendiente y contribuir a que las élites proyectaran una imagen humanista y liberal de su actuación. A pesar de ello los sectores subalternos procuraron disputar los límites previstos a su incorporación y actualizar las potencialidades abolicionistas de los buenos dispositivos.

Para alcanzar estos objetivos se exploran, en primer lugar, leyes sancionadas, debates parlamentarios y prensa del período en los tres países señalados, rastreando sus diálogos y sus lógicas. La idea de rastrear sus "lógicas" apunta a dar cuenta de cuáles son los supuestos subyacentes en términos de visualización de la libertad, de la población de color, de los ciudadanos deseados, etc. En segundo lugar, se reseña la circulación de estas leyes entre sectores populares dando cuenta, por un lado, de prácticas de circulación e interpretación de las mismas en acciones de tipo colectivo y excepcional y, por el otro lado, del uso a escala individual y en el ámbito judicial de las posibilidades ofrecidas por estas leyes y también sus límites.

\section{Diálogos abolicionistas}

Los cambios en la sensibilidad moral hacia la esclavitud estaban en marcha años antes de la era de las revoluciones hispanoamericanas a partir de la multiplicación de críticas religiosas a la institución, la circulación de las obras ilustradas francesas, las campañas abolicionistas inglesas y la experiencia haitiana, entre otros factores.

El movimiento juntista iniciado en Hispanoamérica en 1810, como consecuencia del avance francés sobre la península y el selectivo rechazo americano de la autoridad del Consejo de Regencia, dio lugar a un marcado proceso de experimentación e innovación legislativo por parte de las elites americanas. En las regiones donde se desplegaron activas iniciativas autonomistas, el discurso de la retroversión de la soberanía a los pueblos, la exaltación de la idea de derechos naturales y el rechazo del dominio español como injusta esclavización de los americanos por tres siglos jugaron un rol central. No es casual que en tales ciudades y regiones se generaran algunas de las primeras leyes (más y menos duraderas) de reforma parcial o radical del tráfico y la institución esclavista mismas.

Aquí vamos a centrarnos en los casos de Chile, Colombia y Argentina ya que los nuevos gobiernos que aspiraron establecerse allí tuvieron en común el rechazo a las autoridades peninsulares y la disposición a introducir cambios tempranamente de cara a la esclavitud. 
Vamos a abordar dos momentos de estas políticas y debates (el primero centrado en la década de 1810 y el segundo en la de 1820) dado que marcan coyunturas políticas y abolicionistas precisas.

\section{Diálogos sobre la esclavitud en contextos revolucionarios}

Hacia abril de 1811, los diputados españoles peninsulares y americanos comenzaron a discutir en Cádiz la posibilidad de introducir modificaciones graduales al régimen esclavista. No es casual que quien primero hiciera tales propuestas en el seno de la convención fuera el novohispano José Miguel Guridi Alcocer (dado que los insurgentes mexicanos habían dictaminado el fin de la esclavitud ya en octubre del año anterior). En las sesiones preparatorias del congreso Alcocer expuso un plan de abolición gradual de la esclavitud compuesto por la prohibición inmediata de la trata de esclavos, la liberación de los recién nacidos y la suavización de la condición servil. Semejante propuesta no fue tratada en el pleno de las Cortes donde, en cambio, se discutieron las proposiciones del asturiano Agustín Argüelles en pos de abolir el "tan infame tráfico" de esclavos "no sólo es opuesto a la pureza y liberalidad de los sentimientos de la Nación española, sino al espíritu de su religión ..." . Arguelles, decía recordar "la memorable noche del 5 de Febrero de 1807, en que tuve la dulce satisfacción de presenciar en la Cámara de los Lores el triunfo de las luces y de la filosofía; en que se aprobó el Bill de abolición del comercio de esclavos"6. Dejaba claro, no obstante, que su moción no trataba de "manumitir a los esclavos de las posesiones de América, asunto que merece la mayor circunspección, atendido el doloroso ejemplar acaecido en Santo Domingo"7. La sensibilidad que provocaba esta cuestión se hizo patente en la moción del diputado cubano Andrés Jáuregui quien pidió que tales propuestas no se trataran en público para que los comentarios no trascendieran en la prensa e inquietaran los ánimos en su isla, "una importante posesión desde todos los puntos de vista y cuya paz debe asegurarse con la prudencia de no tratar estos asuntos" ". Así, las soluciones más radicales fueron relegadas y la constitución gaditana lejos de abolir el tráfico impuso condiciones especialmente

5 Diario de sesiones de las Cortes de Cádiz, No 185, 2/4/1811, p. 811.

6 La Aurora de Chile, Número 11. Jueves 23 de Abril de 1812. Tomo I.

7 Diario de sesiones de las Cortes de Cádiz, № 185, 2/4/1811, p. 811.

8 Los temores del diputado cubano no eran diversos de aquellos que habían expresado los representantes de la "la perla de las Antillas" durante los debates de la Asamblea Constituyente francesa. Cfr. Geggus, "Racial Equality" (nota 3). 
gravosas para que los afrodescendientes libres accedieran a la ciudadanía9 Sin embargo, los debates cuya circulación Jáuregui procuraba restringir, resonaron en América y llegaron hasta la remota y díscola capitanía chilena donde en abril de 1812 La Aurora de Chile publicaría extractos no sólo del moderado discurso de Argüelles contra el tráfico sino también las más radicales propuestas de Alcocer ${ }^{10}$. No era casual que en Santiago de Chile tales expresiones se publicaran abiertamente. En octubre de 1811 el recientemente organizado Congreso Nacional, dominado entonces por el sector más radical, había acordado en un mismo decreto tanto la prohibición del tráfico de esclavos como la liberación de los vientres ${ }^{11}$.

Para diciembre de ese año las buenas nuevas chilenas circulaban en prensa rioplatense. La Gaceta de Buenos Aires publicaba en dos números un "Resumen de las providencias del gobierno de Chile", una arenga del gobierno de ese país exhortando a diversas clases de apoyos. Entre ellos decía,

"Esclavos: preciosa porción aunque infeliz de la humanidad: nuestras embarcaciones jamás conduxeron del Africa a vuestros progenitores ... Ya es libre vuestra posteridad. Chile es el primer país de la América española que proclama ese natural derecho. Agradecednos lo que es posible por ahora... luego veréis los principios suaves y benéficos que modificarán la triste servidumbre, hasta reduciros a la clase de hijos"12.

De este modo, las elites chilenas se declaraban libres del pecado de la trata $\mathrm{y}$ apostaban a una abolición gradual a partir de la liberación de los niños ${ }^{13}$.

9 Ver al respecto, Josep Fradera, "Raza y ciudadanía. El factor racial en la delimitación de los derechos políticos de los americanos": Gobernar colonias (Barcelona 1999), pp. 51-69; Scarlett O'Phelan Godoy, "Ciudadanía y etnicidad en las Cortes de Cádiz”: Cristóbal Aljovín de Losada/Nils Jacobsen (eds.), Cultura politica en los andes. (1750-1950) (Lima 2007), pp. 267-289; Manuel Chust/Ivana Frasquet (eds.), Los colores de las independencias iberoamericanas. Liberalismo, etnia y raza (Madrid 2009).

${ }^{10}$ La Aurora de Chile, Tomo I, Número 11. Jueves 23 de Abril de 1812 y No 12, Jueves 30 de Abril de 1812.

${ }^{11}$ El decreto establecía "desde hoi en adelante no venga a Chile ningun esclavo; i que los que transiten para paises donde subsista esta dura lei, si se demoran por cualquiera causa i permanecen seis meses en este reino, queden libres por el mismo hecho; que los que al presente se hallan en servidumbre, permanezcan en una condicion que se les hará tolerable la habitud... i, sobre todo, el consuelo de que sus hijos que nazcan desde hoi, serán libres, como espresamente se establece por regla inalterable." LVI. Sesion del Congreso Nacional, 11 de octubre de 1811.

12 Gaceta de Buenos Aires, № 11, Martes 10 de Diciembre de 1811.

${ }^{13}$ El tono redentor del texto - común a las políticas abolicionistas de la época - habla por sí mismo. Lo curioso es que la historiografía de la esclavitud y abolición latinoamericana lo ha sostenido largamente. 
Las políticas abolicionistas en el Río de la Plata, sin embargo, no comenzarían sino hasta abril de 1812 cuando el Triunvirato declarara prohibido el tráfico de esclavos:

"Por obsequio a los derechos de la humanidad afligida, a la conducta uniforme de las naciones cultas, a las reclamaciones de las respetables autoridades de esta capital, y a las consecuencias de los principios liberales que han proclamado y defienden con valor y energía los pueblos ilustres de las Provincias Unidas del Río de la Plata"14.

Los debates gaditanos referidos a la abolición de tráfico o la libertad de vientres no habían circulado de modo directo en la prensa porteña como tampoco lo hicieron las noticias sobre Haití en el periódico colonial ${ }^{15}$, si bien lo hicieron a través de papeles sueltos, gacetas extranjeras e incluso oralmente.

El decreto no sólo prohibía la trata sino que, como en Chile, se declaraba que "todos los esclavos de países extranjeros que de cualquier modo se introduzcan desde este día en adelante queden libres por el sólo hecho de pisar el territorio de las Provincias Unidas" ${ }^{16}$. De este modo, ambos espacios adoptaban el principio del "suelo libre", es decir, que por el sólo hecho de pisar tierras chilenas como argentinas, los esclavos serían liberados ${ }^{17}$. Los conflictos diplomáticos a que estas declaraciones dieron lugar, impulsaron su posterior limitación ${ }^{18}$.

${ }^{14}$ Registro Oficial de Leyes de la República Argentina (en adelante RORA), tomo I (1810-1821) (Buenos Aires 1879), p. 168. Al mismo tiempo el decreto establecía que los barcos que llegaran hasta el 25 de mayo del año siguiente serían expulsados y aquellos que llegaran luego de esa fecha serían incautados y los esclavos liberados. Eso sí, el gobierno cuidaría "de aplicarlos a ocupaciones útiles".

${ }^{15}$ Desde 1806 la Corona habría instruido sobre la limitación de la circulación de tales noticias en los virreinatos. Archivo General de la Nación Argentina (en adelante AGN), Sala IX, 25-2-15, 368. Reales Órdenes, "Para prevenir una revuelta de esclavos, por haber salido de Santo Domingo algunos emisarios para su organización, se manda prenderles como á toda persona de Color que venga de esa isla“. 14/09/1806.

16 RORA (nota 14), p. 194.

${ }^{17}$ Sobre el principio del "suelo libre" establecido en otros contextos y sus implicancias ver el dossier coordinado por Keila Grinberg en Slavery \& Abolition. A Journal of Slave and Post-Slave Studies 32:3 (2011) y Sue Peabody, "There are no slaves in France". The political culture of race and slavery in ancient regime (New York 1996) y "La question raciale et le « sol libre de france »: 1'affaire Furcy": Annales. Histoire, Sciences Sociales 64:6 (2009), pp. 1305-1334. De modo similar este principio se consideraba establecido desde 1772 por jurisprudencia en Gran Bretaña a partir del caso Somerset que estableció la libertad de un esclavo llevado a Inglaterra por su amo de Boston y huido luego de dos años. Defendido por un grupo de abolicionistas logró ser declarado libre.

${ }^{18}$ Sobre los reclamos y presiones del Brasil, ver Keila Grinberg, "Escravidão, alforria e direito no Brasil oitocentista. Reflexões sobre a lei de 1831 e o "principio da liberdade" na 
Junto a la abolición de la trata, la libertad de vientres se transformó en la vía gradual de abolición discutida y preferida por las élites republicanas. Era una ley que prometía conciliar el derecho de propiedad presente con la aspiración a la liberación futura. La ley chilena en particular se volvió un modelo explícitamente citado y discutido.

En Buenos Aires, en agosto de 1812 un "habitante de Luxan" escribía al periódico editado por el grupo más radical de la revolución rioplatense - la Sociedad Patriótica - un artículo dirigido "a los esclavos y sus hijos". En el mismo aseguraba que aunque su libertad no pudiera decretarse momentáneamente (por el "sagrado derecho de propiedad" y porque por el "abatimiento y servidumbre sois casi incapaces de conduciros desde luego por vosotros mismos"), ella pronto llegaría. Y señalaba, en clara referencia a Chile, éste "es el voto de algunas felices regiones de nuestro continente que han tenido la fortuna de sancionar ya el primer decreto de la naturaleza ..."19.

Unos meses más tarde, en enero de 1813, en el marco del primer congreso constituyente para las Provincias Unidas, la abolición de la trata sería reiterada y la libertad de vientres decretada para los niños nacidos luego del 31 de ese $\operatorname{mes}^{20}$. A esa política de abolición gradual le seguiría rápidamente un "Reglamento para la educación y ejercicio de los libertos" en el cual se establecía que éstos quedarían bajo el patronato de los amos de sus madres y no podrían gozar plenamente de la libertad sino hasta los 16 años las mujeres y 20 años los varones ${ }^{21}$. La condición jurídica era equiparable en muchos sentidos a la esclavitud dado que el patronato daba derecho a los amos a exigir los servicios de los menores y (luego de los dos años) este podría venderse y comprarse.

El modelo de abolición gradual continuaría viajando y en diciembre de 1813, el presidente dictador del Estado de Antioquia (antiguo virreinato de Nueva Granada, estado que había separado su destino de la metrópolis y

fronteira sul do Impero brasileiro": José Murilo de Carvalho (ed.), Nação e cidadania no Impero. Novos horizontes (Río de Janeiro 2007), pp. 268-285, aquí pp. 274-275. La aplicación de este principio y más tarde de la abolición total en Chile, provocaría los mismos tipos de reclamos, esta vez, de las autoridades argentinas.

${ }^{19}$ El Grito del Sur, № 6, 18 de agosto de 1812, p. 48.

${ }^{20}$ El decreto sostenía que "Siendo tan desdoroso como ultrajante a la humanidad, en que en los mismos pueblos que con tanto tesón y esfuerzo caminan hacia su libertad, permanezcan por más tiempo en la esclavitud los niños..." RORA (nota 14), p. 194. Los debates de la llamada Asamblea del año XIII no se conservan.

${ }^{21}$ Para un análisis de dicho Reglamento, sus supuestos, sus consecuencias y usos judiciales ver Magdalena Candioti, "Altaneros y libertinos. Transformaciones de la condición jurídica de los afroporteños en la Buenos Aires revolucionaria": Desarrollo Económico. Revista de Ciencias Sociales 198 (2010) pp. 271-296. 
de la capital virreinal desde 1810 y actual provincia de Colombia), solicitaba al Congreso la adopción de políticas de abolición y proponía tomar el decreto chileno de octubre de $1811^{22}$. Un año más tarde, en abril de 1814, la Cámara de Representantes del Pueblo del Estado de Antioquia aprobaría una ley de libertad de vientres, redactada por los antioqueños Félix de Restrepo y Juan del Corral ${ }^{23}$. La norma disponía tanto la "libertad de partos" como la prohibición del tráfico y establecía, a su vez, otras vías de emancipación. Por un lado, la obligación "forzosa de todo testador, [de] manumitir por causa de muerte uno de cada diez esclavos teniendo herederos forzosos, y no teniéndolos, la cuarta parte de ellos" ${ }^{24} \mathrm{y}$, por otro, el establecimiento de un montepío que, administrado por juntas de "Amigos de la Humanidad" 25 , permitiría una manumisión anual de esclavos en ocasión de las pascuas.

A estas medidas, pensadas para mejorar la suerte de los esclavos "sacarla de tan funesto estado y colocarla en la clase de ciudadanos", sin embargo, se sumaba una serie de restricciones que dan cuenta de que junto a la voluntad de "conceder libertades" persistían percepciones negativas sobre la población de color que modulando las formas de pensar y regular la abolición. Por un lado - y a semejanza del Reglamento porteño cuya circulación en Antioquia no hemos podido constatar - se establecía que los hijos de esclavos estarían al servicio de los amos de sus madres hasta los 16 años, a fin de retribuirlos por el costo de la crianza y la alimentación. Por otro lado, habilitaba una especie de reversibilidad de la condición de libre al prever vagamente que "El esclavo que habiendo conseguido su emancipa-

${ }^{22}$ En su mensaje del 12 de diciembre de 1813 había sostenido "Ya los papeles extranjeros nos anuncian que el liberal Gobierno de Chile se ha llenado de gloria declarando libres los partos, y abriendo a los padres el camino del honor y de la virtud, con la promesa de su emancipación, a los que se distingan eminentemente en el servicio de la patria”, en línea: http://negrosyesclavos.archivogeneral.gov.co/ portal/apps/php/verdocumento.kwe?nur=M$\mathrm{jE} 4 \mathrm{Njc}=$ \&idioma $=\mathrm{ES}[19-07-2015]$.

${ }^{23}$ Ver al respecto, María Eugenia Chaves, "Esclavos, libertades y república. Tesis sobre la polisemia de la libertad en la primera república antioqueña”: E.I.A.L. 22:1 (2011), pp. $81-104$.

24 "Ley sobre la manumisión de la posteridad de los esclavos africanos y sobre los medios de redimir sucesivamente a sus padres, extendida y propuesta para su sanción a la Cámara de Representantes del Pueblo, por el Excelentísimo Dictador Ciudadano Juan B. del Corral”, en línea: http://negrosyesclavos.archivogeneral.gov.co/portal/apps/ php/verdocumento.kwe?nur=MjE4MDE=\&idioma=ES [15-07-2015].

${ }^{25}$ Es interesante resaltar que la fórmula "amigos de la humanidad" era la utilizada por la francesa Sociedad de Amigos de los Negros en sus escritos. Ver « Adresse aux amies de l'humanité; par la société des amis des noirs, sur les plans de ces travaux » Lue au comité le 4 juin 1790 Reimpresa en La Révolution française et l'abolition de l'esclavage, tomo VIII, Documento 3, (Paris 1968), pp. 1-4. 
ción abusase de ella, será suspendido en el ejercicio de sus derechos y entregado a las juntas hasta que se haya reformado" ${ }^{26}$.

El carácter restrictivo y disciplinador de esa medida no sería aislado ni novedoso. Las propuestas abolicionistas europeas y americanas existentes habían previsto siempre diversos tipos de control sobre los emancipados. Así lo habían hecho desde los panfletos de la francesa Sociedad de Amigos de los $\operatorname{Negros}^{27}$, hasta las propias constituciones de la Haití independiente ${ }^{28}$, pasando por los panfletos abolicionistas ingleses ${ }^{29}$ y las tempranas aboliciones de los estados del norte de los Estados Unidos ${ }^{30}$.

De este modo, las políticas abolicionistas más importantes desplegadas por antiguas colonias en los inicios de la década de 1810 propusieron una serie de soluciones frente al problema de la esclavitud y la guerra que resulta interesante poner en diálogo para comprender. Estas políticas, a su vez, abrieron un conjunto de nuevos desafíos con los que élites y plebe lidiaron de modos diversos.

La política chilena de 1811 fue más tímida y gradual pero, a diferencia de los decretos rioplatense y antioqueño, no estableció un patronato para los libertos recién nacidos, ni los sometió a un régimen jurídico específico ni a medidas especiales de control. Los decretos rioplatenses, por su parte, fueron radicales en su enunciación inicial pero se volvieron más restrictivos y paternalistas a partir de disposiciones ad-hoc. De este modo, de declarar libre a todo aquel que pisara el suelo argentino se pasó a excluir de este principio a los sirvientes de extranjeros que estuvieran de paso y, de declarar libres a los hijos de esclavos se pasaría a someterlos a un régimen de libertad tutelada y trabajo no remunerado que acortaría las distancias entre el estatus de libertos y esclavos. El decreto antioqueño, por su parte, fomentaba la aceleración de las manumisiones por las vías testamentaria y filantrópica pero a su vez abría la puerta a controles similares a los rioplatenses e incluso, más directamente, a la reesclavización de negros y mulatos que "abusaran" de la libertad concedida.

Estas innovaciones habían respondido entonces a un posible sincero cambio en la sensibilidad hacia la esclavitud, a una voluntad (y a presiones, como veremos más adelante) de hacer coherente la libertad política (la

26 "Ley sobre la manumisión" (nota 24). Énfasis agregado.

${ }^{27}$ Ibidem.

${ }^{28}$ Ver Carolyn E. Fick, "The Haitian Revolution and the Limits of Freedom. Defining Citizenship in the Revolutionary Era": Social History 32:4 (2007), pp. 394-414.

${ }^{29}$ Seymour Drescher, Capitalism and antislavery. British mobilization in comparative perspective (New York 1987).

${ }^{30}$ Joanne Pope Melish, Disowning Slavery. Gradual Emancipation and "Race" in New England, 1780 (New York 1998), pp. 50-78. 
independencia de España) con la libertad personal (de los esclavos), y también a la necesidad concreta de ganar apoyos para la revolución ${ }^{31}$. Al mismo tiempo, ellas hicieron salir a la luz, o incluso profundizaron, "problemas" más antiguos percibidos por las élites: la cuestión de la igualación/desaparición de las castas, el escepticismo sobre la capacidad de los antiguos esclavos para ser ciudadanos y la cuestión de la educación y el control de la plebe de color y la plebe en general. En adelante, las respuestas disciplinadoras, lejos de reducirse, se multiplicarían.

Con excepción de las rioplatenses, las demás leyes abolicionistas perdieron vigencia temporal o definitiva de la mano de la reinstalación de autoridades realistas. A pesar de ello, Chile (1823) produjo una abolición completa mucho antes que Argentina (1853) e incluso Colombia (1851), con una población esclava mucho más numerosa, lo hizo dos años antes ${ }^{32}$.

\section{Diálogos en las nuevas repúblicas y la regulación de la emancipación esclava}

Al ritmo de las revoluciones, la regulación de la vida de los esclavos continuó mutando. En los años veinte asistimos a un conjunto de nuevas leyes en torno al fin de la esclavitud que serán más y menos radicales según el caso pero tendrán en común una visión pesimista sobre las capacidades ciudadanas de los esclavizados y por tanto una creciente o más explícita vocación de controlarlos.

Los antioqueños volverían a discutir el futuro de la esclavitud en los años veinte pero ya en un proceso de integración en un proyecto de unidad política mayor, la gran Colombia. Reunidos los representantes de las diversas provincias en Cúcuta de 1821 debatieron y sancionaron una nueva ley de libertad de "partos" - con un alcance territorial más amplio y algunas modificaciones - salvando el hecho de que la Constitución, diseñada para reglamentar el nuevo espacio, no hizo menciones a la cuestión. Se impuso

${ }^{31}$ Por cuestiones de espacio hemos dejado fuera de análisis otra vía central de emancipación de los esclavizados en el contexto de las guerras que fue su reclutamiento para los ejércitos. En el Río de la Plata y Nueva Granada fueron el modo más arriesgado pero rápido de acceder a la libertad. Ver, entre otros, Peter Blanchard, Under the Flags of Freedom. Slave Soldiers and the Wars of Independence in Spanish South America (Pittsburgh 2008).

${ }^{32}$ El trabajo no quiere sugerir que las decisiones se tomaron sólo considerando el imaginario de las elites y sus diálogos. Las condiciones de posibilidad de las políticas adoptadas en los diversos espacios, ligada a la proporción de esclavos y población de color libre existente y el rol de éstos en la economía local, fueron algunos de los elementos centrales que aquí no se analizan. 
en adelante lo que Almario llamó una "inclusión condicionada del elemento negro en el proyecto nacional" 33 .

$\mathrm{Su}$ inspirador fue nuevamente el antioqueño Félix de Restrepo. De acuerdo a María Eugenia Chaves, para Restrepo la cuestión era central ya que la esclavitud contradecía el derecho natural, la religión y carecía de fundamentos legales ${ }^{34}$. Sin embargo, al introducir consideraciones sobre su oportunidad y conveniencia económica, la radicalidad potencial de su retórica terminaba reducida a una propuesta de manumisión gradual de los niños y manumisiones pagas o graciosas de los adultos.

En esta línea, y profundizando la voluntad de control de los libertos expresada en 1814, la ley sancionada dispuso la libertad de los hijos de esclavas manteniendo su sujeción a los dueños de éstas hasta los 18 años; reafirmó la prohibición del tráfico y la organización de colectas para manumitir esclavos. Eliminó las manumisiones testamentarias forzosas pero estableció un impuesto sobre los testamentos; instó a la formación de "juntas de manumisión" para la administración de tales fondos y la organización de los actos de liberación - los cuales ya no debían celebrarse en las pascuas sino durante las fiestas patrias de diciembre ${ }^{35}$. Finalmente, la ley preveía - de un modo más específico que la de 1814 - que dicha junta velaría "sobre la conducta y procedimientos de los expresados jóvenes, a fin de que promueva con el Gobierno el que se les destine a oficios y profesiones útiles" ${ }^{36}$.

En Chile las noticias de estas disposiciones del Congreso gran colombiano se recibieron pronto, pero el camino tomado fue más radical ${ }^{37}$. Instalada la patria nueva y reafirmada la vigencia de las leyes de abolición gradual del ' 11 , los debates reemergieron hacia 1823. En junio el senador chileno José Miguel Infante - luego de dar cuenta de serias transgresiones a la ley de libertad de vientres y de relatar tratos crueles que se les daba a los esclavos en el país (y no sólo durante "la tiranía") - hizo en el Parlamento una moción para

${ }^{33}$ Oscar Almario García, Castas y razas en la independencia neogranadina, 18101830. Identidad y alteridad en los orígenes de la Nación colombiana (Bogotá 2012), p. 96.

${ }^{34}$ Chaves, "Esclavos, libertades" (nota 23).

${ }^{35}$ Sobre la organización de estos actos públicos de manumisión entre 1821 y 1851 ver Dolcey Romero Jaramillo, "Manumisión, ritualidad y fiesta liberal en la provincia de Cartagena durante el siglo XIX": Historia Crítica 29 (2005), pp. 125-147.

${ }^{36}$ Ley del 21 de julio sobre "Libertad de partos, manumisión y abolición del tráfico de esclavos", en lìnea: http://negrosyesclavos.archivogeneral.gov.co/portal/ apps/php/legislacion.kwe [15-07-2015].

${ }^{37}$ Mercurio de Chile, $\mathrm{N}^{\circ} 12,25$ de septiembre de 1822. 
"dar un grande ejemplo i una sancion solemne a la opinion de toda la tierra, i al reconocimiento de los derechos imprescriptibles de todos los individuos de la especie humana" y "declarar libres a todos los esclavos existentes" 38 .

La propuesta del senador era realmente radical ya que preveía liberarlos inmediatamente y sin mediar indemnizaciones para los amos. El Director supremo rápidamente objetó ese punto solicitando que se conciliaran "todos los derechos y los intereses". El Senado, que había aprobado la moción de Infante, insistió en la redacción original y preguntando retóricamente "si la propiedad pecuniaria, suponiendo que existiese, había de ser más sagrada que el derecho de libertad inherente a todos los hombres...". En su propia respuesta negativa rechazaba las indemnizaciones dado que el erario no podía "reconocer sobre sí una deuda en orden a la servidumbre que tiene desaprobada ..." 39 .

A pesar de críticas, contrapropuestas y resistencias desde el ejecutivo, la prensa y la oposición, la ley fue promulgada por el Director el 24 de julio tal como la votara el senado. Ella constaba de tres artículos: el primero reafirmaba la ley de vientres, en el segundo la libertad de quienes pisaran suelo chileno por un día y finalmente declaraba que "Cuantos hasta hoy han sido esclavos, son absolutamente libres desde la publicación de este acuerdo"

La amplitud de la ley era revolucionaria, las respuestas fueron reaccionarias. Desde supuestos petitorios colectivos de esclavos solicitando continuar como tales, hasta peticiones de "madres de familia" contra la abolición, pasando por artículos periodísticos que alertaban sobre la miseria, hambre y holgazanería en la que caerían a quienes se "sacaba de una esclavitud aparente para entregarlos a la verdadera de los vicios y la mendicidad"42.

Estas últimas objeciones coincidían con las que habían expresado el director Ramón Freire y su secretario Mariano Egaña en el trámite de la ley. Ellas habían sugerido que era necesario no sólo establecer indemnizaciones sino mecanismos de control de la laboriosidad de los esclavos y esclavas

${ }^{38}$ Senado Conservador, Sesión 37, del 23 de Junio de 1823. Sesiones de los cuerpos legislativos de la República de Chile (1810-1845), Tomo VII-1823 (Santiago de Chile, 1889), p. 222.

${ }^{39}$ Guillermo Feliú Cruz, La abolición de la esclavitud en Chile (2da. ed., Santiago de Chile 1973), p. 77.

${ }^{40}$ Ibidem, p. 38

${ }^{41}$ Ibidem, pp. 93-94.

${ }^{42}$ El tizon republicano, citado en Feliú Cruz, La abolición (nota 39), p. 89. 
tras la emancipación ${ }^{43}$. Frente a la negativa del Senado sancionaron la ley pero limitaron su potencial inclusivo a través de un decreto fuertemente restrictivo de las libertades de los emancipados. La policía estaría encargada de otorgar boletos que comprobaran la libertad de los sujetos siempre que le constase que "el esclavo va a ocuparse en algún ejercicio honesto, y que es apto para él". En el caso de las antiguas esclavas debían comprobar "la honradez de la casa a donde pasa[ban] a morar" dejaría a la persona como libre pero viviendo bajo el patronato de su antiguo amo.

La abolición por ley fue luego reemplazada por el artículo 11 de la constitución que, sancionada en diciembre de 1823 y redactada por Juan Egaña (padre del ministro), disponía que "En Chile no hay esclavos: el que pise su territorio por un día natural será libre". Este artículo con pequeñas modificaciones no dejaría de estar presente en las sucesivas constituciones chilenas y es posible que su redacción fuera retomada en el artículo 15 de la constitución que en 1853 abolió la esclavitud en Argentina ${ }^{45}$.

También en los años veinte en el Río de la Plata - donde el gobierno de unidad nacional había desaparecido y las provincias entraron en un proceso de organización autónoma ${ }^{46}$ - hubo diversas políticas que tendieron a multiplicar los controles sobre los antiguos esclavos y la población de color en general.

En primer lugar, se reguló la creación de "Asociaciones Africanas" para controlar el uso del espacio público por los afrodescendientes y facilitar la libertad de los esclavizados, siempre a través de la sólita práctica de pagar por ella. Estas asociaciones fueron sometidas al control policial y debieron perfeccionar su capacidad de tejer alianzas estratégicas con los diversos gobiernos de turno para ser autorizadas a desarrollar sus propios objetivos, centralmente culturales ${ }^{47}$. En segundo lugar, en el marco de las guerras con el Brasil hacia 1826 se favoreció el ingreso de africanos tomados en operaciones de corso en calidad de libertos. De este modo, se los repartió entre

${ }^{43}$ Ibidem, p. 85 y http://www.dibam.cl/Recursos/Contenidos/Archivo\%20Nacional/ archivos/Freire1823PDF.pdf [15-07-2015].

${ }^{44}$ Archivo Nacional Histórico. Fondo Ministerio del Interior. Vol.32. f 268-268v.

${ }^{45}$ Dicho artículo declaraba: "En la Confederación Argentina no hay esclavos: los pocos que hoy existen quedan libres desde la jura de esta constitución...". Se trata de un artículo que las Bases de Alberdi, texto inspirador de la carta, no consideraban.

${ }^{46}$ Sobre este proceso ver, José Carlos Chiaramonte, Ciudades, provincias, estados. Orígenes de la Nación Argentina (1800-1846) (Buenos Aires 1997).

${ }^{47}$ Ver Oscar Chamosa, "To Honor the Ashes of Their Forebears. The Rise and Crisis of African Nations in the Post-Independence State of Buenos Aires, 1820-1860": The Americas. A Quarterly Review of Inter-American Cultural History 59:3 (2003), pp. 347-378. 
"patronos" que, a cambio de recibirlos, eran autorizados a recibir sus servicios durante cuatro o seis años, según el caso. Toda una red de distribución de mano de obra gratuita puede adivinarse a partir de la lectura del archivo de policía (autoridad ante la cual se tramitaban las solicitudes). También se diseñaron medidas de control de estos libertos, incluso para cuando estuvieran en posesión de su libertad plena. De este modo, el camino de la esclavitud a la libertad continuó siendo tutelado y más lento de lo que una lógica binaria puede hacer suponer ${ }^{48}$. En tercer lugar, en octubre de 1831 se habilitó la enajenación de esclavos introducidos como sirvientes ${ }^{49}$. Si bien los amos debían registrar sus esclavos ante la policía y la venta podía ser eventual, en la práctica fue un subterfugio para la reactivación del tráfico. Así se juzgó cuando dos años más tarde se decidió volver a cerrar este tráfico.

De este modo, con políticas intermitentes de apertura y cierre del tráfico; con el diseño de prácticas de control y tutela de esclavos, libertos y negros libres, y sin una clara retórica abolicionista circulando en la esfera pública, se cerraban las dos décadas tras la revolución.

Pero ¿qué impacto pudieron tener la nueva retórica libertaria y las nuevas leyes y decretos entre sus potenciales "beneficiarios"?

\section{Circulación, interpretación y uso de las leyes abolicionistas por los sectores subalternos}

La circulación de leyes, decretos y opiniones sobre el tráfico y la esclavitud no se agotó en el privilegiado círculo de las élites. En parte, porque los periódicos comenzaron a circular más activamente y muchos eran leídos en voz alta en reuniones, parroquias y pulperías llegando sus noticias a públicos más vastos. En parte, porque quienes los leyeron o escucharon tales anuncios desarrollaron expectativas, ideas y acciones en torno a esas leyes, procurando hacer uso de aquellas existentes, luchando por generar ciertas interpretaciones de ellas e incluso promoviendo la sanción de otras. En este apartado discutiremos dos dimensiones de esa participación: por un lado un uso colectivo y de alcances insurreccionales y, por el otro, un uso individual que da cuenta de cómo las leyes lejos de ser meras concesiones de las élites fueron derechos por los que esclavos y libertos debieron luchar y cuya vigencia e interpretación disputaron en los tribunales.

${ }^{48}$ AGN, Archivo del Departamento de Policía desde el año 1812, 1827-1830, Comunicaciones varias.

${ }^{49}$ Aurelio Prado y Rojas, Nueva recopilación de leyes y decretos de la provincia de Buenos Aires, tomo I, Nº 1180 (Buenos Aires 1877), p. 41. 


\section{Rumores y usos colectivos}

La circulación e impacto popular de las leyes de abolición gradual en Chile fue casi inmediato. En su crónica de los sucesos de octubre de 1811 Manuel Antonio Talavera - partidario realista - escribía:

"Es increíble la impresión que hizo en los ánimos de los esclavos el bando antecedente, el orgullo y osadía que han concebido con la esperanza de la libertad futura de sus hijos. Los propios esclavos se conceptúan ya en aquella esfera, con tal que manifiesten el patriotismo al nuevo Gobierno"so.

Tal es así - manifestaba - que apenas sancionada la ley de vientres la Junta recibió una representación pagada por la colecta de un alto número de esclavos de Santiago de Chile (los testimonios rondan entre 300 y mil) en la que se ofrecían los servicios de éstos para las armas a cambio de su liber$\operatorname{tad}^{51}$.

La propuesta plebeya no fue bien recibida por el gobierno y sus impulsores fueron presos. Ella da cuenta, sin embargo, de un proceso de organización de los esclavizados de la ciudad en pos de promover más disposiciones favorables a su libertad. Es importante subrayar en este sentido que - a diferencia de otros espacios - las noticias sobre la revolución de Santo Domingo y otros alzamientos esclavos eran frecuentes en la prensa chilena $^{52}$.

En la prensa editada en Buenos Aires, como señalamos, la difusión de estas noticias no era frecuente a inicios de la década (aunque sí lo sería luego). Sin embargo, en diciembre de 1811 la Gaceta de Buenos Aires publicó el mencionado informe sobre las "providencias del gobierno de Chile" en las que se daba cuenta del otorgamiento de la libertad a los hijos de los esclavos. ¿Podía esa noticia tener efectos disruptivos siendo que ninguna medida favorable a los esclavos había sido tomada aún por las autoridades revolucionarias? ¿Los esclavos de las Provincias Unidas podían ser

${ }^{50}$ Manuel Antonio Talavera, Revoluciones de Chile. Discurso histórico, diario imparcial, de los sucesos memorables acaecidos en Santiago de Chile por un vecino testigo ocular, en lìnea: http://www.historia.uchile.cl/ CDA/fh_article/0,1389,SCID\%253D20151\%2526ISID\%253D405\%2526PRT\%253D20148\%2526JNID\%253D12,00.html [19-07-2015].

${ }^{51}$ Ibidem.

${ }^{52}$ Ver por ejemplo. La Aurora de Chile, Número 1. Jueves, 13 de Febrero de 1812. Tomo I. "Noticias Sacadas del Periódico Inglés, The Times, Publicado en Londres, a 3 de Septiembre de 1811. Coronación del Rey negro de Haití (alias). Isla de Santo Domingo. Relativa a la Coronación de Henri Christophe"; La Aurora de Chile, $\mathrm{N}^{\circ} 10$, Jueves, 16 de Abril de 1812, "Martinica, 17 de Octubre. Sobre un conato de insurrección de esclavos" y $L a$ Aurora de Chile, Número 11. Jueves 23 de Abril de 1812, Sin título [Relativo a un complot tramado por el Emperador de Haití contra las autoridades de Jamaica]. 
interpelados por la retórica abolicionista chilena? En Mendoza (justo al otro lado de la cordillera de Santiago) la respuesta fue afirmativa. A inicios de mayo de 1812 una conspiración de esclavos fue descubierta por las autoridades. La supuesta rebelión había sido organizada por un grupo de morenos libres y esclavos que habrían preparado un plan para robar armas y exigir a los amos y las autoridades su liberación. Beatriz Bragoni, quien reconstruyó el proceso con detalle, mostró que la población morena mendocina se hallaba politizada por el clima revolucionario, y particularmente expectante en torno a las novedades que el gobierno de Buenos Aires podía introducir en su estatus. La agitación había aumentado especialmente por esos días de la mano de la difusión de las noticias sobre la libertad de vientres decretada en Chile, la supuesta "integración de libertos a la milicias" en Buenos Aires y el ejemplo de una rebelión de negros en "las islas de Santo Domingo" que había logrado liberar a los esclavos atacando violentamente a los amos ${ }^{53}$. ¿Cómo habían llegado tales rumores y noticias? A través de papeles pero también de personas. Las Gacetas - conteniendo artículos sobre valerosos esclavos que recuperaban la libertad por defender la patria, sobre la liberación de los vientres chilena o sobre la conversión del Regimiento de patricios de pardos y morenos en veterano ${ }^{54}$ - habían sido leídas en voz alta en "juntas de morenos". Uno de los responsables de esas lecturas había sido Joaquín Fretes, un negro libre proveniente de Chile quien podía dar detalles y ser la prueba viva de las nuevas leyes. La rebelión, más allá de su fracaso, mostró el impacto que las promesas de libertad e igualdad hechas por la revolución podían tener en el escalón más bajo de la sociedad colonial. El enorme proceso judicial culminó sin castigos dado que, con el cambio de gobierno en Mendoza y la declaración de libertad de vientres en el enero siguiente, los severos cargos perdieron gravedad.

También en Antioquia los esclavos fueron interpelados por el nuevo lenguaje revolucionario. En agosto de 1812, el tribunal del cabildo de Medellín recibió un memorial en el que 206 esclavos a nombre de los más de diez mil de la jurisdicción y alrededores, solicitaban una explicación sobre si era cierto que se les había concedido la libertad ${ }^{55}$. Los esclavizados

${ }^{53}$ Beatriz Bragoni, "Esclavos, libertos y soldados. La cultura política plebeya en Cuyo durante la revolución”: Raúl Fradkin (ed.), ¿Y el pueblo dónde está? Contribuciones para una historia popular de la revolución de independencia en el Río de la Plata (Buenos Aires 2009).

${ }^{54}$ Gaceta de Buenos Aires, $\mathrm{N}^{\circ} 47$ del 2 de mayo de 1811, N $\mathrm{N}^{\circ} 70$ del 10 de octubre de $1811 ; \mathrm{N}^{\circ} 11$ del 10 de diciembre de 1811 . Estas son las noticias que pensamos que probablemente les pudieron impactar.

${ }^{55}$ María Eugenia Chaves, ““Nos, los esclavos de Medellín”. La polisemia de la libertad y las voces subalternas en la primera república antioqueña": Nómadas 33 (2010), pp. 43-55, aquí: p. 44. 
deseaban saber si, y en realidad interpretaban que, la declaración de los derechos naturales del hombre a la igualdad, a la libertad y a la propiedad proclamados por la Constitución antioqueña en 1812 los concernía y quedaban por ella liberados.

Como en Santiago y en Mendoza, la petición fue interpretada como una conspiración de esclavos y alertó gravemente a las autoridades. La investigación judicial capitular se cerró solicitando la publicación de las normativas correspondientes,

“[...] para que llegue a noticias de los encaprichados en la falsa idea de que ya son libres y se precavan de la seducción de los individuos que se complacen en introducir con sus conversaciones el desorden y error en nuestra sociedad"56.

Chaves - quien analizó en detalle el memorial - sostiene que los congresistas antioqueños no habían imaginado esta reacción popular "sencillamente porque el saber letrado constitucional en el que se expresaban sus revoluciones no consideró que esta población podría ser parte de la nueva repúbli$\mathrm{ca}{ }^{\prime 57}$. Es probable que parte de las élites no lo consideraran posible o deseable, pero creemos que, más que una imposibilidad de concebir esa inclusión, lo que signó el período fue la apertura del problema de la definición de la ciudadanía, de quienes serían aceptados como parte "el pueblo"58.

Chaves reconstruye la centralidad de las voces subalternas para interpretar y ampliar el polisémico concepto de libertad contemporáneo. De modo que, no sólo la cultura letrada pudo definir los contornos de ese lenguaje de libertades sino también los propios esclavizados. En este sentido, pensamos que el espacio de los tribunales fue central. Allí encontramos condensados imaginarios y estrategias subalternas esbozadas tanto en los momentos claros pero excepcionales de organización y manifestación colectiva así como en cotidianas y rutinarias demandas individuales de justicia.

\section{La libertad en los tribunales: tres ejemplos}

Las leyes dictadas, como hemos señalado, no equivalieron a su unánime interpretación y mecánica aplicación. Más bien abrieron campos de disputas y nuevos vocabularios e instrumentos con los que luchar por la libertad. En el caso de Chile, Carolina González Undurraga ha señalado cómo en

${ }^{56}$ Ibidem, p. 48.

${ }^{57}$ Ididem, p, 45.

${ }^{58}$ Elías Palti, El tiempo de la política. El siglo XIX reconsiderado (Buenos Aires 2007), pp. 103-159. 
diferentes tipos de demandas (solicitudes de papel de venta, querellas por malos tratos, demandas de libertad) por parte de los esclavos la apelación al "nuevo sistema" y la acusación de "despotismo" de los amos o jueces, fueron herramientas importantes para activar judicialmente derechos ${ }^{59}$. Junto a la nueva gramática política y judicial, nuevas definiciones de derechos se abrieron. Así, apenas restaurado el gobierno criollo en 1817, los hijos de esclavos (más específicamente sus familiares) se movilizaron para validar la ley de libertad de vientres convenientemente desconocida por los amos tras el avance realista. El proceso iniciado en junio de 1817 por Juan Farías solicitando la libertad de su hijo Mateo Eustaquio es particularmente ilustrativo al respecto dado que el fiscal actuante no sólo solicitó el reconocimiento de la libertad para el caso particular sino que, para evitar futuras situaciones similares, pidió a

"Vuestra Excelencia tener a bien hazer publicar por Bando, o incertar en la Gazeta Ministerial la rebalidacion de la Soberana disposicion para la inobservancia que de ella ha havido en el tiempo de la despotica, y tiranica dominación" ${ }^{60}$.

De hecho así se hizo y la ley fue ratificada.

En el caso de Antioquia, como en Chile, se generaron tensiones sobre la vigencia de las leyes patriotas durante la reconquista. Así, una vez recuperada la independencia y sancionada la nueva ley de vientres colombiana, se multiplicaron las consultas sobre el estatus de los niños nacidos entre marzo de 1816 y la ley de 1821. Sin embargo la definición del gobierno sobre los años intermedios fue distinta. Podemos tomar como ejemplo el caso llevado adelante en 1824 por el Procurador General protector de esclavos Manuel Corral a nombre de Remigio, esclavo de José Ignacio Varela. Allí las tensiones entre soberanías en disputa y sus consecuencias en la vida de los esclavos se hicieron expresas. Mientras Remigio demandaba su libertad en nombre de la ley de 1814 dado que su partida mostraba que había nacido el $1^{\circ}$ de octubre de 1816, el amo señalaba que "aunque se dice que algunos abogados de esta provincia han fallado en favor de que la clase del gobierno intermedio" sea declarada libre, esa "no es una decisión que hace ley ..." ${ }^{\circ 1}$.

${ }^{59}$ Carolina Gonzalez Undurraga, Esclavos y esclavas litigantes. Justicia, esclavitud y prácticas judiciales en Santiago de Chile (1770-1823), Tesis para optar al grado de Doctora en Historia, El Colegio de México, 2013.

${ }^{60}$ Capitanía General, volumen 55, fojas 303-307, 1817, reproducido en Por carta de libertad y papel de venta. Esclavos y esclavas demandando justicia. Chile, 1740-1823. Documentación judicial por carta de libertad y papel de venta. Estudio introductorio y transcripción de fondos de Carolina González Undurraga (Santiago de Chile 2014).

${ }^{61}$ Archivo Histórico de Antioquia, Colonia, Documentos Históricos, Negros y Esclavos, Vol. 4, Leg. 38, f. 522. 
Varela alegaba que tal interpretación contradecía el sentido "literal y natural" de la ley del '21. La respuesta del procurador - que ya no era Corral procuraría abonar la teoría opuesta, afirmando que el sentido del artículo 15 de esa misma ley favorecía la libertad de aquellos que la hubieran obtenido durante los gobiernos republicanos ${ }^{62}$. Sin embargo, cerraba su escrito pidiendo que se consultara a una superioridad para conseguir - como pidiera el fiscal chileno - una "declaratoria que sirviese de regla general" y mientras, se suspendiera toda "determinación y reclamo en cuanto a las libertades de esta naturaleza" ${ }^{63}$. No sabemos qué ocurrió con Remigio pero, dado que llevaba sus 8 años viviendo como esclavo y que la ley preveía que los libertos prestaran "obras y servicios" hasta los 18 , es muy probable que continuara sino esclavizado, al menos bajo la "tutela" de Varela, por diez años más.

En el caso del Río de la Plata los esclavos recurrieron a los tribunales, apelando a los nuevos valores del gobierno patrio, para pedir su libertad. No por ello fueron siempre exitosos en su empresa ${ }^{64}$. Tal fue el caso del esclavo letrado Francisco Estrada y su mujer Joaquina quienes pidieron ser liberados por haber desobedecido a su amo español fugado a Montevideo y haberse acogido "al sistema generoso de la Patria, cantamos los himnos de la libertad, y uniendo nuestros deseos, nuestros corazones con los santos sentimientos del sistema justo de la Libertad"65. A pesar de su encendida retórica patriota no obtuvieron una respuesta favorable y murieron peticionando a una justicia que más tarde les ordenaría que "en lo sucesivo no incomoden a sus amos, ni perturben la atención de las autoridades con solicitudes infundadas y maliciosas, bajo apercibimiento que se escarmentará como corresponda" ${ }^{66}$.

A su vez, si bien la ley de vientres no perdió vigencia dado que el gobierno patrio no retrocedió en manos realistas, su vigencia creó otro sin número de conflictos en torno al cuidado de los libertos, la compra-venta o traspaso del patronato, la "compra" de la libertad anticipada por parte los libertos, el traslado de esclavas embarazadas a otros países, entre otras. Un ejemplo de estas luchas fue protagonizada por la esclava parda Petrona en 1823. Residente en Santa Fe, Petrona fue vendida a Ana Monterroso supuestamente vecina de Buenos Aires - a través de un apoderado. Al poco tiempo de arribada a la ciudad porteña, su nueva ama comenzó los aprontes

\footnotetext{
62 Ibidem, f. 522v.

${ }^{63}$ Ibidem, f. 523 y $523 \mathrm{v}$.

${ }^{64}$ Candioti, "Altaneros" (nota 21).

${ }^{65}$ AGN, Sala IX, $23-8-3$, Administrativos, Legajo 29, Expediente 984, f. $1 \mathrm{v}$.

66 Ibidem, f. 20 y $20 \mathrm{v}$.
} 
para viajar a Montevideo de donde era realmente originaria. Embarazada, la esclava se resistió al traslado y a arriesgar la libertad de su hijo en un país donde los hijos de esclavas no eran liberados al nacer. Para convencerla, Monterroso hizo redactar una carta de libertad para el "Postumo" pero la esclava no cedió. Sin poder retrasar más su regreso, la flamante ama partió a Montevideo y dejó a María a cargo de Francisco Belautegui y Eugenia Saravia para que éstos arreglaran su venta. Pasados 10 días sin lograr la venta, los apoderados proyectaron embarcarla. Para evitarlo Petrona recurrió a la justicia de paz, donde expuso sus temores. El juzgado devino un campo de lucha por los alcances de la ley de libertad de vientres. Mientras Saravia sostuvo que la libertad del niño estaría asegurada por la carta de libertad librada por un escribano, el defensor replicó que no era posible dar la libertad a quien la tenía de nacimiento, es decir "a favor de un feto que ya es libre y no necesita de ella sino para ser sacado del país en perjuicio de su libertad" 67 .

El juez de primera instancia prohibió el embarque en nombre del decreto del 10 de agosto de 1821 inserto en el registro oficial $\mathrm{N}^{\circ} 12$ que inhibía precisamente la salida de esclavas embarazadas a países extranjeros donde - como argüía el defensor - "no se tiene ni noticia de la libertad que se le ha dado aquí" ${ }^{68}$. Los apoderados de Monterroso insistieron argumentando que era "preciso que el juzgado tenga en cuenta que si es venerable la libertad, no lo es menos el derecho de propiedad, ambos son dogmas sagrados en lo político y legal" ${ }^{\prime 69}$. En junio se intercambiaron los últimos escritos y el expediente finaliza sin más acciones. Presumiblemente Petrona logró al menos que su hijo naciera liberto en Buenos Aires.

En estas cotidianas disputas judiciales los esclavizados procuraron ampliar sus márgenes de autonomía e incluso conquistar su libertad. Si en esta esfera de conflictos más individuales los diálogos expresos con experiencias contemporáneas de otras latitudes son más difíciles de encontrar, no deja de sorprender la similitud de problemas y estrategias desplegadas en puntos geográficamente muy distantes ${ }^{70}$.

${ }^{67}$ AGN, Tribunal Civil, 23, M-15, 1823, f. 3.

${ }^{68}$ Ibidem, f. 3.

${ }^{69}$ Ibidem, f. 4.

${ }^{70}$ Esta gran continuidad en las formas de pleitear puede pensarse en parte consecuencia de la aplicación plurisecular en América de las normas hispanas de regulación de la esclavitud que modularon las formas de tramitar papeles de venta, solicitudes de justo precio, redhibitorias, reclamos de coartación, entre otros. Sobre estas normativas cfr. Manuel Lucena Salmoral, Los códigos negros de la América Española (Alcalá 1996). 


\section{Conclusiones}

A lo largo del trabajo procuramos reconstruir algunos de los diálogos interamericanos en torno a la definición de estrategias y políticas de abolición de la esclavitud. Buscamos enfatizar que, junto a la consideración de condiciones e ideales locales, las elites, pero también los esclavos, estuvieron atentos a experiencias y políticas extranjeras contemporáneas. Las élites, por su parte, compartieron una común imagen redencionista de sí mismas, se visualizaron y presentaron a sí mismas como generosas y sensibles almas que otorgaban la libertad a hombres "miserables" que debían estar agradecidos por tales concesiones. Esta imagen entraba en tensión con el discurso mismo que había hecho de la libertad y la igualdad un derecho natural y no una gracia otorgada. Esa tensión fue precisamente señalada muchas veces por los propios esclavizados en luchas colectivas o individuales en la que procuraron hacer realidad las interpretaciones más radicales de tales principios.

Las políticas antiesclavistas, a su vez, jugaron un rol clave en el enfrentamiento material pero también simbólico con la antigua metrópolis. Con ellas, el primer liberalismo americano intentó diferenciarse de la moderación peninsular. Más adelante, y en el marco de otros conflictos territoriales, las políticas abolicionistas también se presentarían como muestras de la superioridad del sistema político propio: tal sería el caso de la retórica rioplatense frente al imperio brasileño desde 1820 o de la retórica humanista mexicana de cara al sistema esclavista norteamericano en el marco de su conflicto por Texas.

En todos los casos, esas políticas fueron también utilizadas para autocelebrar a los nacientes estados. De allí que la libertad de vientres rioplatense rigiera desde la fecha del primer congreso constituyente; de allí también que las fiestas de manumisión (en el caso colombiano) se hicieran en el contexto de la celebración de la independencia.

Otro rasgo común de estas políticas es que corrieron paralelas a procesos de estereotipación, racialización y subalternización así como a intentos de control de la población de color manumitida. Por ello es que la lucha por la plena integración de los esclavizados y sus descendientes fue más larga que lo que sugieren las fechas de las aboliciones formales. Podemos decir que no es casual que en los tres casos analizados predomina hasta hoy una celebración del mestizaje y una invisibilización de los africanos y afrodescendientes.

Es necesario aclarar que difícilmente los procesos abordados agotan la multiplicidad y multidireccionalidad de los diálogos abolicionistas en curso. Nuestra intención era mostrar que, escapando al marco de las histo- 
rias nacionales, era posible empezar a reconstruir una fina y desatendida red de diálogos sobre la esclavitud y los modos de abolición a escala continental e incluso atlántica, al nivel de las élites pero también de los sectores subalternos. Y a su vez, resaltar que esos diálogos, muchas veces en la forma de rumores, movilizaron acciones de resistencia colectiva. Finalmente, señalamos con breves ejemplos como estas leyes de abolición gradual o incluso total (como en Chile) abrieron campos de disputa judicial por derechos y no cambios automáticos en la condición jurídica y social de los antiguos esclavizados. 
